\title{
Graduação em Saúde Coletiva: limites e possibilidades como estratégia de formação profissional
}

\author{
Undergraduate on Public Health: limits and possibilities \\ as a professional education strategy
}

M aria Lúcia M agalhães Bosi ${ }^{1}$

Jairnilson Silva Paim²

${ }^{1}$ Departamento deSaúde Comunitária, Faculdadede Medicina, Universidade Federal do Ceará. Rua Prof. Costa M endes 1.608/50 andar, Rodolfo Teófilo. 21943-570 Fortaleza CE. malubosi@ufc.br

2Instituto deSaúde Coletiva, Universidade Federal da Bahia.
Abstract This article aims to call into question Public $\mathrm{H}$ ealth as a field for professionalization by systematizing theoretical, social and ethical-political bases for undergraduate education. We also attempt to record the trajectory in formulating undergraduate courses in that field and, more re cently, the emergence of these projects in Brazilian Universities. In Brazil, the current projects are a result of institutional experience gained in Public $\mathrm{H}$ ealth teaching in different undergraduate courses in the field of health. Additionally, there is also a teaching tradition in non-degree and master's and PhD graduate courses. International experiences from similar courses, as well as orientation from international agencies represent important information for such initiatives. Furthermore, policies targeting social inclusion and the expansion in the number of student places in higher education have been propelling the movement. There is also the realization that the Brazilian Public Health System demands new actors able to provide answers which are both different and complementary to those offered by traditional undergraduatecourses. While several institutions are in the stage of offering this education to society, this artide presents a set of elements which are derived from re flection in the epistemological, sociological and political-sanitary spheres.

Key words Undergraduatecourses in publichealth, Degree in public health, $\mathrm{H}$ ealth professionals, Human resources, Public health
Resumo 0 presenteartigo problematiza a Saúde Coletiva como âmbito de profissionalização, sistematizando alguns fundamentos teóricos, sociais e ético-políticos de uma formação em nível de graduação. Para tanto, recupera a trajetória em que se vem dando a formulação desses cursose, mais recentemente, sua emergência nas instituições de ensino superior brasileiras. No Brasil, tais projetos resultam do acúmulo no ensino da Saúde Coletiva em diferentes cursos de graduação na área da saúde, acrescido da tradição na pós- graduação lato e stricto sensu, tendo dentre os seus desdobramentos o reconhecimento da pertinência de fomentar novas estratégias de formação. M ais recentemente, políticas voltadas à inclusão social e à expansão do ensino superior vêm impulsionando o movimento, ao que se soma a constatação de que o Sistema Único de Saúde demanda novos atores, com capacidade de dar respostas diferenciadas e complementares àquel as possi bilitadas pelas graduações tradicionais. No momento em que diversasinstituições seencontram em fasede oferta dessa formação à sociedade, este artigo apresenta um conjunto de elementos derivados da reflexão nos planos epistemológico, sociológico e políticosanitário, visando a contribuir para um diálogo acerca da emergência desse projeto no contexto brasileiro.

Palavras-chave Graduação em saúde coletiva, Profissionais de saúde, Recursos humanos, Saúde pública, Saúde coletiva 
Introdução

Embora se possa afirmar que, no contexto brasileiro, o movimento de criação de cursos degraduação em Saúde Coletiva é bastante recente, a ideia de uma graduação em Saúde Pública não é nova e nem deve ser creditada aos autores brasileiros que vêm refletindo sobre o tema no Brasil ou aos protagonistas da implantação de cursos no momento atual. A criação de uma graduação em Saúde Coletiva já vem sendo proposta há quase duas décadas e discutida no meio acadê mico deforma mais sistemática, desde2002, ainda que distintas iniciativas relacionadas ao ensino da Saúde Pública em nível de graduação já se encontrem efetivadas em muitos países.

U sando a Internet como ferramenta de busca de informações, um levantamento realizado em $2002^{1}$ buscou identificar experiências de cursos no cenário internacional. A despeito da diversidade, dos limites que se impõem a comparações entre os distintos cursos e transposições de características da formação nesses países com o que se pretende no Brasil, o documento apre senta um quadro bastante ilustrativo da difusão e das especificidades desses cursos. Não obstante tais limitações que ficam a exigir novas análises, ao que se soma a escassez de informações verificada em certos momentos da busca, foram localizados cursos de graduação em Saúde Pública em vários continentes, em especial, nos países do chamado "primeiro mundo".

Seguindo o mesmo caminho de busca, em maio de 2009, constatamos um crescimento de cerca de $30 \%$ no número de cursos informados, em relação a 2002, o que aponta uma tendência de expansão e acreditação dessa formação. Nos Estados Unidos, há uma associação de escolas de saúde pública (http://www.asph.org) à qual se afiliam, no momento atual, quarenta escolas credenciadas eoito escolas associadas, além de nove programas.

No que concerneao Brasil, enquanto em 2002 não havia nenhum curso dessa natureza, existem atualmente quinze de cursos de graduação plena em Saúde Coletiva, com previsão de vários outros a serem ofertados para o próximo ano, em um movimento que parece se expandir por todas as regiões do país, a mai oria deles adotando a denominação desse campo. $N$ as experiências levantadas, pode-se perceber que a formação mais precoce de profissionais habilitados em Saúde Pública parece ser hoje uma preocupação e uma tendência mundial ${ }^{2}$.
Ainda que, para os propósitos deste artigo, à primeira vista não pareça fazer sentido a distinção entre Saúde Coletiva (SC) e Saúde Pública (SP), a proposta de criação de cursos de graduação com a primeira denominação é tributária da construção do campo da Saúde Coletiva no país e da sua vinculação ao projeto da Reforma Sanitária Brasileira (RSB). Nesse particular, a delimitação teórico-conceitual e epistemológica desse campo e a análise da conjuntura que apontam certos desafios para a RSB e o Sistema Ú nico de Saúde (SUS) 3,4 compõem a base argumentativa para a implantação dos referidos cursos. N esse sentido, o presente artigo visa a problematizar a Saúde Coletiva como espaço de profissionalização, sistematizando alguns fundamentos teóricos, sociais e ético-políticos de uma formação em nível de graduação.

\section{Antecedentes}

Ainda que se reconheça certa arbitrariedade ao se demarcar a gênese de processos sociais, podese, no que se refere à criação dos cursos de graduação em SC, recuperar um percurso pontuado por alguns marcos. Dentre os movimentos que se julga de importância nessa trajetória sem, contudo, pretendermos Ihes atribuir a "autoria", cabe mencionar uma série de reuniões, no início da década de oitenta, no âmbito do movimento crítico em saúde, com o propósito de discutir os centros formadores na graduação, voltados ao ensino da epidemiologia, das ciências humanase sociais e do planejamento, isto é, cuidar do ensino da SC na graduação das profissões de saúde.

N essa perspectiva, uma das primeiras iniciativas da Abrasco (Associação Brasileira de Pósgraduação em Saúde Coletiva), ao lado da defesa das residências em medicina preventiva esocial, foi a realização de uma reunião nacional, em 1983, para discutir o ensino da SC na graduação. Àquela época, embora a intenção de uma graduação em SC não se explicitasse, já prevalecia a ideia de que um investimento nessa formação profissional constituía estratégia importantepara a proposta da RSB, ao ponto de os participantes recomendarem a organização de um " $N$ úcleo de Graduação" na Abrasco, além de uma articulação dessa entidade com a Associação Brasileira de Educação M édica (ABEM) e com os departamentos de medicina preventiva e social ${ }^{5}$.

Com o desenvolvimento da Abrasco, a aposta na construção de uma rede nacional de pós- 
graduação em Saúde Coletiva ampliou a massa crítica para formação na área, com a disseminação de conteúdos específicos nas diversas graduações em saúde e a formação de profissionais para assumir liderança na gestão dos sistemas de saúde.

Pode-se afirmar que ambas as estratégias foram exitosas. Em qualquer região/estado do Brasil, identifica-sea presença de profissionais deSC e, ao longo dos últimos trinta anos, o movimento foi bem sucedido ${ }^{6}$, sendo hoje a área considerada madura e internacionalmente reconhecida. A rede de programas de pós-graduação se expandiu e se consolidou, saltando dos seis cursos existentes no momento da criação da Abrasco (UERJ, EN SP, D M P-USP, FSP-USP, Ribeirão Preto e UFBA ) para 57 em 2009. O conjunto de programas vem adotando estratégias inovadoras - ressaltando-se dentre elas a criação do Fórum $\mathrm{N}$ acional de Coordenadores de Pós-graduação em Saúde Coletiva, com o apoio da Abras$\mathrm{co}$, aspecto que se expressa em documentos produzidos nos últimos anos ${ }^{7,8}$.

Contudo, quando se examinava o campo, constatava-se a falta da carreira de sanitarista, sugerindo a necessi dade de se graduar profissionais de SC. Tal constatação deu origem a distintos eventos, nos quais o tema tem sido o objeto de reflexão e de debate. Nesse particular, duas oficinas representam marcos fundamentais no percurso e julgamos oportuno mencioná-las.

Em setembro de 2002, com o apoio do M inistério da Saúde (MS) e contando com a participação de representantes da Abrasco, OPAS, Fiocruz, universidades, entre outros, foi realizado I Seminário e Oficina de Trabalho "Graduação em Saúde Coletiva: pertinência e possi bilidades", organizado pelo Instituto de Saúde Coletiva (ISC/ UFBa). Naquela oportunidade, diversos participantes reconheceram a viabilidade, a pertinência e a necessidade de um curso de Saúde Coletiva em nível de graduação ${ }^{9}$.

Em julho de 2003, tem lugar uma segunda oficina, como atividade prévia ao VII Congresso Brasileiro de Saúde Coletiva, em Brasília, ao que se soma a inclusão na programação oficial do referido congresso o painel intitulado "É tempo de termos uma graduação em Saúde Coletiva?", cuja audiência ganhou destaque dada sua diversidadee magnitude, atraindo cerca de oitocentos participantes.

Antecipando-se às controvérsias explicitadas do decorrer congresso, a revista Radis ${ }^{10}$, anunciava um "debate bom": Vai estourar no Abrascão ( 70 Congresso Brasileiro de Saúde Coletiva) a discus- são, protelada atéagora, acerca da formação profissional em Saúde Coletiva. 0 repórter dessa coluna, Fontes Fidedignas, informa que não passa desse fórum o 'racha' entre os partidários da criação do curso de graduação em Saúde Coletiva eos partidários do deixa-como-está [...] É esperar pra ver".

Independentemente da caracterização simplificada dos oponentes na nota acima, os debates destacaram a "pertinência e possibilidades" de uma graduação na área. No caso do painel referido, contou com a manifestação de entidades de classe, estudantes, pesquisadores, coordenadores de cursos e outros coletivos, a exemplo da Rede Unida. Conforme se antecipava, verificouse um acirrado debate entre os que defendiam a SaúdeColetiva como parteda formação das profissões existentes e aqueles que argumentavam em torno da oportunidade da "nova graduação", sem que isso implicasse prejuízo na formação dos demais profissionais de saúde que, também, contribuem para o campo da Saúde Coletiva. Desse modo, o cerne do embateparecia se referir à pertinência dessa formação específica na graduação. Entretanto, boa parte dos atores entendia haver uma disputa de monopólio entre as profissões existentes diante da "nova graduação" proposta, conforme sugere a seguinte opinião: Penso que o SU S não precisa de mais uma categoria profissional, mas de médicos, enfermeiras e demais profissionais com novo perfil, novas competências e novos compromissos técnicos e políticos [...] Criar uma graduação em Saúde Coletiva é dizer queo trabalho quepropomos aos demais profissionais de saúde é, em verdade, privativo de um novo profissional11".

Embora tal interpretação não se apoiasse no desenvolvimento teórico- conceitual do campo, muito menos em evidências, sinalizava para possíveis disputas corporativas. Lembrando que a definição de uma profissão supõe a configuração de um corpo de conhecimentos e um elenco de valores que fornecem identidade para ação dos sujeitos, ressaltava-se naquele debate que a Saúde Coletiva já dispunha de um conjunto de habilidades e competências, bem como de um "ideal de serviços" em defesa da vida e da saúde do público: Não se justifica, portanto, esperar o tempo requerido para a graduação nos diversos cursos da área da saúde, para depois capacitar os profissionais em Saúde Coletiva. Por melhor que tenha sido o ensino das disciplinas dessa área nos cursos de graduação, as competências adquiridas são limitadas e subalternas ao model o médico hegemônico [...] 0 SUS tem pressa para reorientar 0 modelo assistencial dominante ${ }^{12}$. 
Não obstante as recomendações da Oficina do VII Congresso no sentido de ampliar o debate, nem a Abrasco nem o M inistério da Saúde viabilizaram tais desdobramentos naquele momento. Algumas universidades, no entanto, deram continuidade aos esforços para a institucionalização da proposta de cursos pelas instâncias e colegiados superiores, visando à sua formalização.

\section{Desenvolvimento recente}

Cerca de cinco anos decorreriam até que se processasse um deslocamento de ênfase no debate que não mais recairia na pertinência, ou seja, no porquê, mas no como implementar essa formação. Para a compreensão desse movimento, emerge como contexto político decisivo o Programa de Apoio a Planos de Reestruturação e Expansão das Universidades Federais (REUNI), instituído pelo decreto $\mathrm{n}-6096$ de 24 de abril de 2007, com o objetivo de "criar condições para a ampliação do acesso e permanência na educação superior, no nível de graduação, pelo melhor aproveitamento da estrutura física e de recursos humanos existentes nas universidades federais" ${ }^{\prime 13}$. N esse contexto, adeptos da graduação em Saúde Coletiva encontraram um solo favorável à sua criação, embora, reitere-se, não tenha sido o REUNI a inspiração da proposta que, conforme vimos, a antecede historicamente, mas, certamente, foi o catalisador de suas bases institucional e material de implantação.

Algumas iniciativas de articulação de instituições proponentes da graduação em Saúde Coletiva foram empreendidas via rede, inclusive com a realização de uma reunião em Belo Horizonte, seguida do Encontro Nacional sobre a Implantação do Curso de Graduação em Saúde Coletiva, em Salvador em agosto de 2008, promovido pela UFBa com o apoio do MS e OPAS, já coincidindo com os primeiros processos de seleção no vestibular.

A despeito de ser hoje essa graduação um projeto já institucionalizado em universidades e bem recebido pela gestão nacional do SUS, isto não significa quehaja um consenso estabelecido, pois ainda persistem distintas leituras e concepções. Contudo, não obstante os diferentes posicionamentos, tal modalidade de formação inegavelmente adere à consolidação do SUS, cuja estabilidade requer profissionais com perfis não visíveis em quantidadeequalidade requerida pelo sistema. Tais perfis têm proximidade mas vão além das funções essenciais propostas pela
OPAS ${ }^{14}$, reconfiguradas no trabal ho desenvolvido pelo CONASS, ao qual se associam as diretrizes curriculares para cursos de graduação, enfatizando princípios e valores centrais na formação do graduado em Saúde Coletiva.

Ao se defender a figura do bacharel em Saúde Coletiva, um elemento importante é que já não mais se coloca a clássica questão: quem formará os formadores? No caso em tela, a expansão e consolidação da pós-graduação deram conta dessa complexa etapa. Nesse sentido, como já antes aludido, papel decisivo foi desempenhado pela Rede Nacional de Pós-Graduação strictu senso e, antes disso, pelas especializações e residências ${ }^{15}$. Contudo, há que considerar as especificidades dessas formações que, a despeito da sua importância, não se confundem com o que se espera de um graduado em Saúde Coletiva. N este momento, é preciso avançar e ousar estratégias, visualizando que a RSB e o SUS necessitam de mais este perfil profissional - o graduado. 0 grifo aqui importa, haja vista a presença, nas discussões travadas sobre esta proposta, de posicionamentos que consideram ser a referida graduação uma alternativa às outras formações na Saúde, em lugar de tomá-la como uma estratégia a mais, que vem se associar à formação da equipe de trabalhadores em saúde, com identidade específica que não se confunde com a dos demais.

Quanto a isso, é preciso ressaltar que, em nenhum plano ou aspecto, se justificaria o "esvaziamento" dos conteúdos atualmente presentes nas demais formações na saúde. Ao contrário, defende-se a radicalização dessa "inoculação" para tomar uma metáfora da biomedicina - a exemplo das proposições mais recentes nas quais não apenas se reconhece a importância desses conteúdos e saberes para as graduações em saúde, mas se afirma: "[...] all undergraduates should have access to education in public health"16.

Considerando-se essa posição, postula-se, no caso brasileiro, a continuidadee, inclusive, 0 aprofundamento, das inserções existentes nas estruturas curriculares das demais formações, bem como sua expansão para outras áreas de formação. Tal posicionamento, a exemplo do queocorre em relação aos núcleos de saberes que moldam muitas outras formações, não conflita e nem elimina a demanda por uma formação específica para o sanitarista, na qual a complexidade dos desafios que se colocam na dimensão coletiva da saúde poderá ser estudada, investigada e abordada com a profundidade e amplitude necessárias. Reconhece-se, portanto, a Saúde Coletiva como um campo científico e âmbito de práticas 
que justificam um processo de profissionalização em novas bases.

Evidentemente, já seformam sanitaristas desde os tempos de Oswaldo Cruz, Carlos Chagas, Geraldo de Paula Souza e Belisário Pena, mas o que está em pauta é se a estratégia tem sido a mais adequada. Será que, para atuar, competentemente, em Saúde Coletiva, precisamos, necessariamente, de um pós-graduado?

Considerando não apenas aspectos relacionados ao custo/benefício, adiante comentados, mas aqueles vinculados à natureza da formação necessária para o enfrentamento das questões de saúde no plano coletivo, acreditamos que não. São necessários jovens profissionais em início de carrei ra, que demarcarão suas trajetórias delineando sua identidade na experiência de ser um sujeito-agente da Saúde Coletiva, sem se submeter a uma "regraduação" ou "desconstrução" ao ingressar com suas formações de origem no campo da Saúde Coletiva, em nível da pós-graduação. Talvez a isso se vincule a nebulosidade observada no que concerne à identidade do campo e dos próprios atores, pós-graduandos, advindos das mais diversas formações da saúde, grosso modo pautadas em núcleos de saberes distantes ou mesmo conflitantes com aqueles que norteiam a identidade profissional da SaúdeColetiva. Coloca-se, portanto, a questão: qual a identidade? Por que uma profissionalização?

Acerca da identidade edo processo de profissionalização no campo da Saúde Coletiva

Deinício, épreciso reafirmar quea SaúdeC oletiva ou mesmo a Saúde Pública, ao contrário do que se supõe em certos círculos, não são especialidades médicas, nem de outras profissões da saúde. As origens da SaúdePública estão relacionadas aos desafios postos pelas condições sanitárias produzidas pela emergência do capitalismo na Europa, com industrialização, urbanização desordenada e aumento da miséria relativa. A "saúde pública" atrelada às escolas médicas foi produto de uma decisão política de uma fundação americana atuando como agentefinanciador, não uma questão técnico-científica ou mesmo da sociologia das profissões.

Esta mesma fundação influenciou a London School of Hygiene and Tropical M edicine no início do século XX, a criação deM inistérios da Saúde nos países latino-americanos, as campanhas sanitárias e as escolas de Saúde Pública do Brasil e do M éxico, entre outras ${ }^{3}$.
Desde 1991, o diretor da OPS questionava a subordinação da Saúde Pública ao campo da medicina ${ }^{17}$. Esta posição foi reiterada pelal Conferencia Pan-americana de Educación en Salud Pública/XVI Conferencia deALAESP18.

No caso da Saúde Coletiva, trata-se de um campo científico e um âmbito de práticas que visa a superar dialeticamente a Saúde Pública convencional ${ }^{19}$. Este campo científico em construção encontra-se na interseção das ciências da saúde e das ciências sociais, com uma natureza epistemológica diferenciada euma prática política distinta. Os conhecimentos nele produzidos podem (tal como se observa em relação a todas as profissões estabelecidas no setor saúde) ser aplicados por distintos sujeitos, mas sustentamos que, da mesma forma como nas demais, existeum corpo básico que dá identidade ao "pensar" e ao "fazer" em Saúde Coletiva, inspirado em um conjunto de valores ("ser"). Este saberfazer-ser se produziu e reproduziu até recentemente na pós-graduação, mas isso não impede, do ponto devista pedagógico etécnico, que elese estruture em uma graduação específica.

Em termos de identidade, ser pós-graduado é um estatuto distinto de graduado. Não obstante se reconheça a "reconfiguração identitária" oportunizada pela pós-graduação em Saúde Coletiva, o curso de graduação deverá ajudar na demarcação mais clara dos contornos dessa identidade. Cabe ressaltar queaidentidadenão éal go que se concede. Ao contrário, deve ser tomada como construção (e reconstrução social), em contextos de incerteza, mais ou menos intensos, mais ou menos duráveis ${ }^{20,21}$, o que implica, evidentemente, relações de poder em um dado momento histórico. Basta revisitar a história das profissões estabelecidas para se concluir o quanto suas identidades se reconstruíram ao longo do tempo, para que se tornassem o que hoje se apresenta sob os rótulos atuais. Assim, é previsível e promissor que seinterrogueessa nova identidade, ou seja, esse fenômeno inaugural da graduação em Saúde Coletiva no Brasil e seus efeitos identitários sobre o campo.

Para além desses interrogantes no que concerneà(s) nova(s) identidade(s), é possível antecipar uma reconfiguração na pós-graduação a partir da existência da graduação, passando por uma espécie de upgrade, uma vez que conteúdos básicos já estarão assegurados, não sendo necessário desenvolver nesse nível fundamentos que já deveriam ser de domínio de quem ingressa em uma formação de pós-graduação. Evidentemente, essa reconfiguração imporá novos desafios, haja vista a necessidade de harmonizar a forma- 
ção de egressos de cursos degraduação com aquela oportunizada pelas demais graduações em saúde e áreas afins à Saúde Coletiva. Assim, há que se considerar a formação prévia do primeiro segmento, sem "fechar portas" a corporações que queiram se pós-graduar nessa área². Tais obstáculos pedem superações que, acredita-se, a consolidação da pós-graduação na área já écapaz de realizar.

Pode-se ainda contra-argumentar: não deveria ser o especialista esse ator, conforme em muitos casos vem se dando? Considera-se que não. Isto por que "especialista", no campo da formação, se reveste de outra conotação e como tal deve ser compreendido. Ao lado disso, a experiência ea literatura ensi nam: 0 el emento queconfere identidade própria ao profissional, essencial na constituição de uma carreira, em especial no âmbito da profissionalização em saúde, não é dado pela especialização. Constrói-se no longo e complexo processo de socialização de saberes formais etácitos - sintetizados na experiência de se graduar em uma dada área e fazer parte de um segmento profissional, seja profissão sociologicamente estabelecida ou ainda em processo. N ão por acaso as graduações (e não as pós-graduações) vem sendo sistematicamente examinadas como base de constituição do que a sociologia das profissões considera "profissão", referencial que se julga de interesse para a discussão em tela e que, dados os limites da discussão, será tão somente sumarizado.

Consoante esse marco teórico, a proposição de uma profissão, no sentido sociológico do termo, deve considerar dois aspectos fundamentais: o saber específico - quelheconfereidentidade e autonomia técnica - e a necessidade social a responder, sem o que não se pode justificá-l la22. Ambos os aspectos não se apresentam como obstáculos para uma graduação em Saúde Cole tiva: há saberes que Ihe são específicos e a necessidade social a que visa responder é evidente e reiterada por distintos atores.

Importa ainda refletir se o fenômeno diz respeito à criação de uma "nova corporação", uma vez que, de longa data, diversas instituições têm se ocupado da formação de sanitaristas no país e no mundo. Conformejá aludido, tal projeto resultou na formação de muitos sanitaristas sem, contudo, convencer se o mesmo vem representando a melhor estratégia que deva ser mantida no atual estágio de desenvolvimento do campo. Sendo assim, a criação dessa graduação, mais que uma nova profissão, versa sobre uma nova estratégia de profissionalização em saúde.
No que concerne à carreira, consoante postulados da sociologia das profissões, grosso modo se constata a criação de cursos antes de a carreira ser regulamentada. A literatura sociológica sobre o tema aponta ser este um fator indutor na política de "recursos humanos", embora, no caso em questão, se antecipe um acesso à carreira aos egressos de formações stricto sensu e lato sensu.

Contudo, a despeito dos elementos elucidativos apontados por autores clássicos nesse domínio ${ }^{23-26}$, não parece prudente antecipar previsões sobre obstáculos ou prováveis "degraus da profissionalização", com que irão se deparar os egressos dessa nova formação. Tampouco se os mesmos seguirão as etapas comuns aos percursos de outros segmentos profissionais no Brasil. Reiteram-se as assertivas de Dubar ${ }^{21}$ quanto ao caráter processual e incerto, portanto, contraditório edialético, quecaracteriza a construção das identidades profissionais e, por conseguinte, sua autonomia técnica e socioeconômica, marca ontológica de uma profissão ${ }^{25}$. É difícil trabalhar com o queéinédito; só a experiência podedesvelar o caminho. Ou, pensando estrategicamente, o fundamental é desencadear processos ${ }^{27}$.

Finalmente, no que concerne à conquista de espaço próprio, expresso no conceito deautonomia, aos que questionam a existência de "um mercado", parece prudente não negligenciar a própria participação do corpo discente e dosfuturos egressos, como atores centrais e protagonistas na criação da carreira e no avanço do processo de profissionalização, bem como a demarcação dos seus espaços ante as profissões existentes, com base no perfil construído ao longo do curso. Trata-se de introduzir a dimensão subjetiva, a marca do vivido e da intersubjetividade no âmago da análise sociológica ${ }^{20,22}$, recuperando o sujeito no processo de profissionalização, 0 que substitui profecias pela ação histórica, queé sempre um devir.

Graduação em Saúde Coletiva: considerações sobre o perfil e modelo deformação

Para além das considerações relativas ao campo eà profissionalização, a concretização do projeto de graduação na área sustenta-se em justificativas tanto de ordem técnica quanto social. Do ponto de vista da relevância social, não há dúvidas de que o processo de implantação do SUS resulta em uma demanda cada vez maior de profissionais de Saúde Coletiva por parte das orga- 
nizações de saúde conquanto as instituições formadoras até o momento não tenham conseguido constituir sujeitos adequados e suficientes a esta nova realidade.

Para suprir esse déficit de profissionais, as instituições componentes do SUS nos seus diversos níveis - municipal, estadual e federal - e até mesmo as organizações do subsistema privado, vêm investindo cada vez mais na educação continuada de pessoal, através de cursos e treinamentos em serviço das mais diferentes modalidades, a despeito de não ser esta sua função precípua.

Em síntese, do ponto de vista técnico, a resposta à questão "por que uma graduação em Saúde Coletiva?" é clara e imediata: porque os nossos cursos de graduação não formam plenamente para a Saúde Coletiva. A isso se acrescente o fato de que a formação desses e de outros profissionais em áreas tradicionais ou mais recentes de conhecimento eintervenção da Saúde Coletiva - promoção da saúde, planejamento e gestão, avaliação em saúde, vigilância epidemiológica, saúdeambiental, bioestatística, vigilância sanitária, etc. - no âmbito restrito da pós-graduação, resulta em um investimento de recursose detempo muito superior ao que se verificaria com a oferta de formação em nível de graduação, sem ser capaz de construir uma identidade profissional clara. Argumenta-se que, na atual estrutura formadora em saúde, quem pretender seguir uma carreira em Saúde Coletiva tem queenfrentar uma formação que se inicia com um curso de graduação, geralmentena área biomédicae, apenas mais tarde, mediante cursos stricto ou lato sensu, alcançar a sua conclusão ${ }^{28}$

Dessa forma, o tempo exigido para a titulação deum sanitarista se prolonga, o que dificulta a preparação de novos quadros para a área. Tal trajetória, na verdade, caracteriza uma reprofissionalização ${ }^{28}$, processo que acaba implicando aumento dos custos sociais dessa formação, sobretudo quando se considera que ela se dá, fundamentalmente, em instituições públicas, ao que se associa o adiamento do ingresso no mercado de trabalho.

Esse processo de (re) profissionalização em dois tempos seimpõe, tendo em vista as distâncias paradigmáticas entrea formação de quem chega à Saúde Coletiva eaquela pretendida como desfecho dessa formação. Um rápido exame da grade curricular das principais especialidades em saúde, origem da maioria dos alunos que acorrem aos cursos de pós-graduação em Saúde Coletiva, leva à constatação da ausência ou insuficiência de um conjunto de conhecimentos em sua formação políticas de saúde, epidemiologia, planejamento e gestão, métodos qualitativos de investigação em saúde, saúde ambiental, demografia, bioestatística, dentre muitos outros exemplos.

Para atender às demandas desse complexo campo, é imprescindível a formação de profissionais orientados por uma concepção interdisciplinar que conjugue elementos do modelo biomédico com conhecimentos oriundos do domínio das ciências humanas e sociais, deslocandose de uma preocupação eminentemente individual para uma atuação na esfera coletivo/populacional. Perante tais "marcas de origem", os cursos de pós-graduação se vêem forçados a oferecer uma formação em Saúde Coletiva, procurando, antes detudo, equacionar essas lacunas ${ }^{28}$. Além disso, a formação requerida implica outro posicionamento não apenas no plano epistemológico mas, igualmente, no plano ético-político.

Ainda que muito se tenha avançado na concepção de saúde para além da ausência de doença, é grande a dificuldade de se colocar em prática propostas como a de promoção da saúde, em sua versão ampliada. Tal dificuldadetranscende a saúde como área de conhecimento, na sua visão tradicional e restrita, pois sua superação requer uma compreensão abrangente do conceito de saúde e dos processos envolvidos na sua determinação ou deterioração, bem como uma abordagem essencialmenteintersetorial. Por intersetorial, além dos aspectos interdisciplinares das áreas de conhecimento associadas à Saúde Coletiva, entende-se também um compromisso ético diante do modo de vida das pessoas, envolvendo aspectos diversos, tais como transporte, lazer, segurança, trabaIho, alimentação, renda, vida afetiva.

Nesse sentido, postula-se que a graduação irá favorecer a qualificação dos futuros sanitaristas de forma dupla. De um lado, possibilitando queesse processo, desdeo seu início, se oriente por outra perspectiva paradigmática, calcada na interdisciplinaridade, modelo quese apresenta mais adequado aos desafios da saúde em nível coletivo. De outra parte, a presença do curso de graduação em Saúde Coletiva poderá proporcionar novas condições e oportunidades para um aprofundamento de conhecimentos e aprimoramento de habilidades e atitudes nos cursos de pós-graduação, possibilitando que esses recuperem sua natureza que muitas vezes seempobrece com versões minimalistas. 


\section{Controvérsiase desafios}

A despeito do reconhecimento, por partedemuitos atores, da rel evância dessa formação que ora se institucionaliza no contexto brasileiro, persistem muitas dúvidas e, mais que isso, desafios, aos quais, em parte, procurou-se responder nos tópicos anteriores. Dentre as discussões travadas, uma das mais centrais é o quanto uma formação de base estritamente biológica este curso deve conter. Freidson ${ }^{25}$, autor já citado, representante da vertentehistoricista da sociologia das profissões, argumenta sobre a centralidade do saber na garantia da identidade eautonomia profissional, sobretudo na área da saúde, na qual a configuração do processo de trabalho em torno da profissão médica confere singularidade à dinâmica da profissionalização, não encontrando paralelo em outros domínios. Assim, interrogase: sendo o sanitarista, um profissional da saúde, o quanto ele deve saber de biologia, do conhecimento do corpo humano ou do reconhecimento de algumas patologias? Quanto inserir acerca das bases biológicas da saúde humana, ou seja, como ancorá-lo à área da saúde fortemente apoiada nas ciências biológicas, sem reproduzir o modelo da biomedicina?

Com base na produção sociológica, além de importante, seria tático fornecer essa sustentação mas não confundindo formação em saúde com fundamentação em biologia ou biomedicina, já que, conforme aludido, não é este o paradigma que se coaduna com a formação pretendida. Evidentemente, determinar essa "dosagem" ideal não constitui tarefa isenta de dificuldades, haja vista a necessidade de dialogar com as demais profissões e, mais que isso, de se relacionar com as distintas corporações no processo de trabalho em saúde. $\mathrm{N}$ ão se deve esquecer, no entanto, que a pós-graduação strictu senso tem fornecido títulos demestre e de doutor em Saúde Coletiva a advogados, arquitetos, cientistas sociais, físicos, assistentes sociais e outros tantos, sem que se tenha questionado o quanto de ciências biológicas el es trazem de suas formações pregressas.

Em termos pragmáticos, um possível caminho para contemplar conteúdos biológicos seria analisar as chamadas "funções essenciais" e estabelecer redefinições no desenho curricular, tarefa que, contudo, escapa aos propósitos deste artigo. Por ora, cabe valorizar as "marcas de origem" das profissões reconhecidas, consideradas paradigmáticas em termos de profissionalização na saúde, lembrando que iniciaram com um saber valorizado, ou seja, com base ampla e específica ${ }^{24}$ capaz deconferir um grau deautonomia técnica em um campo específico ${ }^{25,26}$. Dessa forma, advoga-se uma composição curricular densa, mas não centrada no conhecimento anátomo-clínico ou biológico, uma vez que, conforme já ressaltado, a sua finalidade é formar profissionais capazes de atuar no planejamento, gestão, execução eavaliação de ações de âmbito coletivo e não no atendimento individual. 0 desafio maior desse profissional será responder às novas necessidades decorrentes das mudanças nos distintos espaços de prática, considerando as transformações no mercado de trabalho e na organização dos sistemas de saúde. Quanto a isso, impõe-se outro desafio o da articulação teoria-prática.

Em Saúde Coletiva, práticas integradas constituem componente essencial da formação. Desse modo, o currículo deve atender o objetivo de desenvolver as competências profissionais gerais eespecíficas na área de Saúde Coletiva, prevendo situações que levem os alunos a aprender a pensar, ou seja, recriar o conhecimento problematizando-o; aprender a aprender, realizando a tão propalada articulação pesquisa-ensino; aprender a ser, comprometendo-se com valores e princípios vinculados à democracia, autonomia das pessoas, solidariedade, justiça, emancipação, equidade, dignidade humana, respeito à diferença, entre outros; mobilizar e articular conhecimentos, habilidades evalores conduzindo a uma posição ético-política comprometida com a defesa da vida e da saúde enquanto direito, consoanteo ideário da Reforma Sanitária, uma vez que Saúde Coletiva, enquanto campo de saberes e práxis, não pode ser compreendida em separado desse projeto de reforma social ${ }^{4}$.

Neste sentido, os conteúdos do programa deverão privilegiar o estudo contextualizado, para o que estratégias como seminários interdisciplinares e o currículo flexível permitam ao aluno migrar para outros domínios e núcleos de saberes. A integração com experiências extra-acadê micas, ou seja, com o "mundo da vida", de modo a visualizar não apenas a interdisciplinaridade mas a transculturalidade como possibilidade e valor, poderá produzir novas tecnologias, sobretudo, relacionais. $\mathrm{Na}$ impossibilidade de, nos limites deste texto, especificar a vastidão do espaço potencial para esse novo graduando, assinala-se, contudo, que há que favorecer o processo de construção-desconstrução-reconstrução dos saberes eenunciados científicos, detal forma que represente uma prática de constituição de novos sujeitos. Sendo assim, conforme já aludido, o "mercado de trabalho" se definirá no processo; 
os desdobramentos para as políticas públicas apontarão os limites e as possibilidades ${ }^{29}$.

\section{Comentáriosfinais}

Presentemente, mais que aprofundar aspectos históricos, conceituais, teóricos, epistemológicos, metodológicos, técnicos eoperacionais, importa reiterar um convite para a concretização de uma iniciativa ousada e inovadora: constituir novos sujeitos no campo da Saúde Coletiva. Assim, caberia desenvolver projetos solidários com a Re forma Sanitária, assegurando o envolvimento das pessoas - gente com afeto, projetos, interesses, valores e vontades.

Lutas, contradições, produção de conhecimentos, sonhos, subjetividades, engenho, trabalho e arte compõem a construção da Saúde Cole- tiva na América Latina ${ }^{3}$. Ela aposta na formação de novos sujeitos enuma práxis contra-hegemônica que produz conhecimentos, critica movimentos ideológicos, elabora concepções, forja "ligas" para mudanças e realiza práticas que tomam a saúde, qualidade de vida, direitos humanos, liberdade, emancipação efelicidade como referentes centrais. A conjunção desses elementos na construção da RSB ilustra a especificidade e as potencialidades desse campo científico e âmbito de práticas, capaz de contribuir na consolidação de um SUS, universal, público, equânime, ético, culturalmente sensível esolidário.

Portanto, a Saúde Coletiva encontra-se, na atualidade, em condições de maturidade teórica, metodológica, tecnológica eoperativa suficientes para definir competências e articular valores que permitam a configuração de novas modalidades de profissionalização em saúde.

\section{Colaboradores}

M LM Bosi e JS Paim participaram de todas as etapas da elaboração do artigo. 


\section{Referências}

1. Universidade Federal do Rio de Janeiro. Projeto detalhado de Curso de Graduação em Saúde Coletiva. Rio de Janeiro: UFRJ; 2003.

2. Lee JM. Articulation of undergraduate and graduate education in public health. Public Health Reports 2008; 128(suppl. 2):12-17.

3. Paim JS. Desafios para a Saúde Coletiva no século XXI. Salvador: EDUFBA; 2006.

4. Paim JS. Reforma Sanitária Brasileira: contribuição para a compreensão crítica. Rio de Janeiro: Fiocruz; Salvador: EDUFBA; 2008.

5. Associação Brasileira de Pós-graduação em Saúde Coletiva. III Reunião Nacional de Docentes de Medicina Preventiva e Social. Relatório Final. In: Abrasco. Ensino da Saúde Pública, M edicina Preventiva e Social no Brasil. Vol. 3. Rio de Janeiro: Abrasco; 1984. p.171-187.

6. Lima NT, Santana JP, organizadores. Saúde Coletiva como Compromisso. A trajetória da Abrasco. Rio de Janeiro: Fiocruz/Abrasco; 2006.

7. Kerr LRS, Pontes RJS, Bosi MLM, Magalhães R, Rigotto R. Reflexões acerca da avaliação das pósgraduações brasileiras com ênfase na área de Saúde Coletiva. Physis 2005; 15(1):83-94.

8. Fórum Nacional de Coordenadores de Pós-graduação em Saúde Coletiva. Nota do sobre o novo Qualis periódicos. [acessado 2009 abr 08]. Disponível em: http://www.abrasco.org.br/forumsaudecoletiva/ index.php

9. Universidade Federal da Bahia. Instituto de Saúde Coletiva. Graduação em Saúde Coletiva: pertinência e possibilidades. I Seminário e Oficina de TrabaIho; 2002; Salvador.

10. Toques da Redação. Debate bom. Radis 2003; 11:6.

11. Almeida M. A área é multiprofissional e interdisciplinar. In: Graduação em Saúde Coletiva: sim ou não? Radis 2003; 13:22.

12. Paim JS. O SUS tem pressa para reorientar modelo. Radis 2003; 13:23.

13. Brasil. Decreto no 6.096 de 24 de abril de 2007 . Institui o Programa de Apoio a Planos de Reestruturação e Expansão das Universidades Federais REUNI. Diário Oficial da União 2007; 25 abr.

14. Organização Pan-Americana da Saúde. Funções essenciais em Saúde Pública. [site da Internet] [acessado 2009 jun 02]. Disponível em: http://www. opas.org.br/servico/temas.cfm?CodSubTema $=69 \&$ Area $=$ Conceito

15. Nunes TCM. Democracia no ensino e nas instituições: A face pedagógica do SUS. Rio de Janeiro: Fiocruz; 2007.
16. Gebbie KM, Rosenstock $L, H$ ernandez LM, editors. Who Will Keep the Public Healthy? Educating Public $\mathrm{H}$ ealth professionals for the $21^{\text {st }}$ century. Washington, D.C.: National Academies Press; 2006.

17. Macedo CG. El contexto. In: OPS. La crisis de la salud pública: Reflexiones para el debate. Publicación científica n 540. Washington, D.C.: OPS; 1992. p. 237-243.

18. Informe Final. I Conferencia Panamericana de Educación en Salud Pública. XVI Conferencia de ALAESP; 1994; Rio de Janeiro.

19. Paim JS, Almeida Filho N. A Crise da Saúde Pública e a U topia da Saúde Coletiva. Salvador: Casa da Qualidade Editora; 2000.

20. Schaffel SL. A identidade Profissional em questão. In: Candau VM. Reinventar a escola. Petrópolis: Vozes; 2000.

21. Dubar CA. Socialização: construção das identidades sociais e profissionais. Porto: Porto Editora; 1997.

22. Bosi M LM. Profissionalização e conhecimento: a nutrição em questão. São Paulo: Hucitec; 1996.

23. Wilensky HL. The Professionalization of everyone. In: Grusky O, Miller G, editors. The Sociology of organizations: Basic studies. New York: The Free Press; 1970.

24. Goode W. The theoretical Limits of professionalization. In: Etizioni A. The semi-professions and their organization. London: The Free Press; 1969.

25. Freidson E. La professión médica: Un estudio de sociología del conocimiento aplicada. Barcelona: PenínsuIa; 1978.

26. Freidson E. Medical work in America: Essays on Health. N ew Haven: Yale University Press; 1989.

27. Testa M. Pensamento estratégico e lógica de programação: 0 caso da saúde. São Paulo: Hucitec; Rio de Janeiro: Abrasco; 1995.

28. Bosi MLM, Raggio R, M edronho RA. Reflexões em torno de uma profissionalização em Saúde Pública (Lilacs). Cad Saude Colet 2001; 9(1):5-8.

29. Bosi M LM, Paim JS. Graduação em Saúde Coletiva: Subsídios para um debate necessário. Cad Saude Publica 2009; 25(2):236-237.

Artigo apresentado em 10/06/2009

Aprovado em 08/11/2009

Versão final apresentada em 30/11/2009 